\title{
Design Principle of the Exhibition Project Based on User Research of Planetarium
}

\author{
Xinxiong Liu, Wensi Li, Xuan Li, Wenqi Cao \\ School of Mechanical Science \& Engineering, Huazhong University of Science \& Technology, Wuhan, 430074, China
}

\begin{abstract}
User research of planetarium can effectively obtain the real needs of users. This paper presents the design principle of exhibition project of planetarium, by survey the extent of understanding astronomical knowledge of 300 primary and secondary school students in central China and gains their needs of planetarium exhibition project, make the design more in line with the user's preferences and expectations, provide a theoretical basis for the design and development of exhibition project.
\end{abstract}

Keywords-user research; planetarium; exhibition project; design principle.

\section{RESEARCH BACKGROUND AND PURPOSE}

At present, with the user-centered design concept was put forward, design of product needs close to the user and excavates user's needs, using user research to develop product has become the tendency. For service-oriented venues, user research can improve the success rate of service innovation design, to maximize the product competitive advantage. For users, research make the product closer to their real needs and psychological tendency, and provide users comprehensive service and experience [1].

Planetarium is a science popularization institution which provides learning and mastering astronomy knowledge to the public by combining information technology and display technique and reflecting the wonders of the universe and its cover of scientific knowledge. To understand deeply of the planetarium's target user's preferences and expectations, we investigated the mastery level of astronomical knowledge and astronomy science contents that will be interested in of primary and middle school students which is the main visitors of the planetarium. The design principle of the exhibition project was established according to the analysis results, make the design and development of the exhibition project and plan for thematic content are more targeted.

\section{OUR RESEARCH}

In order to provide real data for the planetarium exhibition project design, we sent questionnaires to 300 elementary and middle school students in central China during April to June 2014, and use a number of formal interviews with different forms. Meanwhile, the conversation was recorded, and we extracted the effective information by organizing the contents of interviews. We did a total of 300 groups of interviews which recorded 303 minutes.

\section{ANALYSIS OF SURVEY DATA}

\section{A. The situation of mastering astronomical knowledge}

The modern astronomical knowledge system is divided into several categories, each category subdivided into several contents. Table I was shown the result of the investigation and statistics of the extent which respondents master the each specific astronomical knowledge.

TABLE I. THE SITUATION OF MASTERING ASTRONOMICAL KNOWLEDGE

\begin{tabular}{|c|c|c|c|c|c|}
\hline $\begin{array}{c}\text { Knowledge } \\
\text { System }\end{array}$ & Content & $\begin{array}{c}\text { Have } \\
\text { no } \\
\text { idea }\end{array}$ & $\begin{array}{c}\text { Did not } \\
\text { know too } \\
\text { much }\end{array}$ & $\begin{array}{l}\text { Under- } \\
\text { standing }\end{array}$ & $\begin{array}{r}\text { Know } \\
\text { very } \\
\text { well }\end{array}$ \\
\hline $\begin{array}{l}\text { 1. The big } \\
\text { bang of the } \\
\text { universe }\end{array}$ & $\begin{array}{c}\text { The big bang of the } \\
\text { universe }\end{array}$ & $32 \%$ & $51 \%$ & $14 \%$ & $3 \%$ \\
\hline \multirow[b]{2}{*}{$\begin{array}{l}\text { 2.Under- } \\
\text { standing of } \\
\text { the milky } \\
\text { way }\end{array}$} & Galaxy distribution & $34 \%$ & $52 \%$ & $14 \%$ & $0 \%$ \\
\hline & $\begin{array}{c}\text { The internal } \\
\text { organizational structure } \\
\text { of galaxy }\end{array}$ & $49 \%$ & $41 \%$ & $10 \%$ & $0 \%$ \\
\hline \multirow{2}{*}{$\begin{array}{l}\text { 3.Under- } \\
\text { standing of } \\
\text { the solar } \\
\text { system }\end{array}$} & The solar system & $16 \%$ & $54 \%$ & $30 \%$ & $4 \%$ \\
\hline & The eight planets & $5 \%$ & $36 \%$ & $47 \%$ & $12 \%$ \\
\hline \multirow{4}{*}{$\begin{array}{l}\text { 4.Evolu- } \\
\text { tion of the } \\
\text { earth }\end{array}$} & The birth of the earth & $41 \%$ & $44 \%$ & $15 \%$ & $0 \%$ \\
\hline & $\begin{array}{c}\text { The Paleozoic } \\
\text { of the earth }\end{array}$ & $46 \%$ & $41 \%$ & $13 \%$ & $0 \%$ \\
\hline & $\begin{array}{l}\text { The Mesozoic } \\
\text { of the earth }\end{array}$ & $18 \%$ & $59 \%$ & $22 \%$ & $1 \%$ \\
\hline & $\begin{array}{l}\text { The Cenozoic } \\
\text { of the earth }\end{array}$ & $18 \%$ & $49 \%$ & $33 \%$ & $0 \%$ \\
\hline \multirow{3}{*}{$\begin{array}{c}\text { 5. Internal } \\
\text { structure of } \\
\text { the sun }\end{array}$} & Solar magnetic field & $49 \%$ & $38 \%$ & $9 \%$ & $4 \%$ \\
\hline & Solar atmosphere & $30 \%$ & $40 \%$ & $22 \%$ & $8 \%$ \\
\hline & Sunlight & $20 \%$ & $51 \%$ & $25 \%$ & $4 \%$ \\
\hline \multirow{3}{*}{$\begin{array}{l}\text { 6. Chinese } \\
\text { Spacecrafts }\end{array}$} & "Long-March" vehicles & $15 \%$ & $60 \%$ & $23 \%$ & $2 \%$ \\
\hline & $\begin{array}{c}\text { “Divine Land” series } \\
\text { spacecrafts }\end{array}$ & $10 \%$ & $53 \%$ & $33 \%$ & $4 \%$ \\
\hline & The series of satellites & $14 \%$ & $49 \%$ & $35 \%$ & $2 \%$ \\
\hline
\end{tabular}




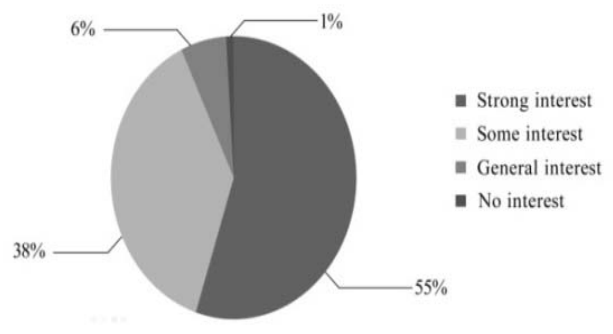

Figure 1. The degree of interest in astronomy

\section{B. The degree of interest in astronomy}

Figure. 1 shows that the $55 \%$ of primary and secondary school students expressed interest in astronomy, 38\% expressed some interest, general interest in $6 \%$, only $1 \%$ of them said that they are not interested in astronomy. From the statistics, more than half of the respondents expressed a great interest in astronomy. Survey results show that with the development of science and technology and human exploration of the universe is in constant depth, the public are more concerned the earth, the universe and the space that we live, and want to gain more knowledge in this area. The planetarium can just use this psychological characteristic of the public, conduct astronomical events for the public interests and popularize the astronomical knowledge.

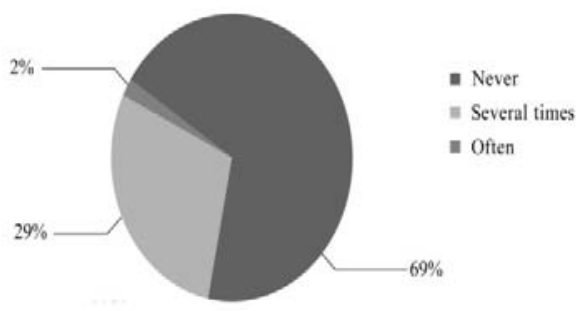

Figure 2. Whether have been to the planetarium

\section{Whether have been to the planetarium}

Figure. 2 shows that $69 \%$ of the primary and secondary school students had never been to the planetarium, frequented by only $2 \%$. The survey shows that very few people had been visited the planetarium. There are many reasons which cause this phenomenon, for example, human attention is not strong enough, restricted by the economical conditions, lack of professional talents and so on. For the planetarium, the reasons why majority of young people's interest for the planetarium reduce are that the publicity and programs are scarce, contents are monotonous and so on. Therefore, before the exhibition project design, the planetarium development planning should be worked out, to promote the planetarium's development and construction.

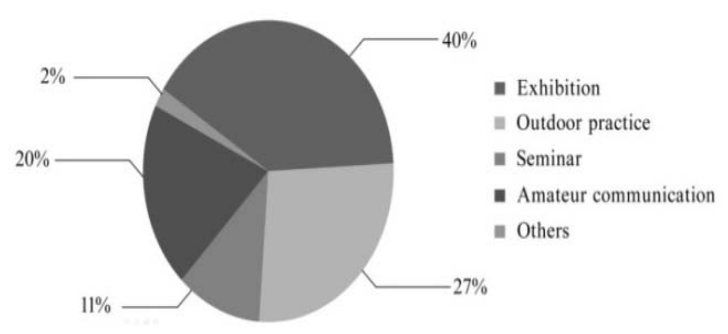

Figure 3. The expected activity which can understand the astronomical knowledge

\section{The expected activity which can understand the astronomical knowledge}

Figure. 3 shows that most people wish understand the astronomical knowledge by visiting astronomy exhibition and outdoor practice (such as observation), accounts for the total number of $40 \%$ and $27 \%$. Then other respondents said informative seminar or amateur communication is also a way to learn astronomical knowledge. Not only planetariums strengthen astronomical observation tools and techniques, but also should enrich science activity forms, to guide the visitors discover the pleasure of astronomy in the exploration course.

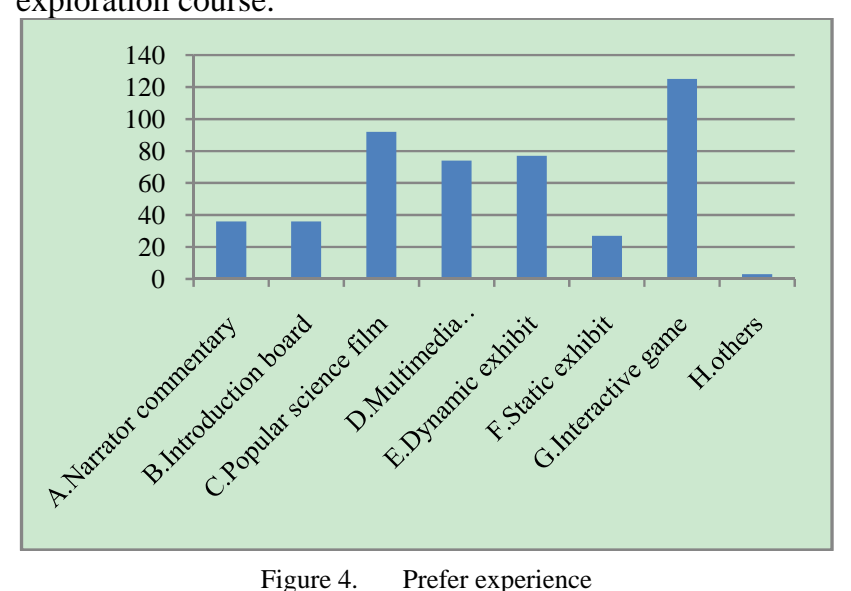

\section{E. Prefer experience}

From Figure.4 it can be seen that the students' favorite experience is interactive game, the follow is watching popular science film, and dynamic exhibit is also popular. From interviews, most primary and secondary school students like to participate in highly interactive series of astronomy activities because they are curious, inquisitive and active by nature. It's undoubtedly important to emphasis on experience and interaction between the visitor and the exhibition for design and construction of the planetarium. It can make planetarium really play its function of science education and inspiring education, meanwhile, it can play a great role in attracting public and expanding influence. 


\section{DESIGN PRINCIPLE OF THE EXHIBITION PROJECT}

\section{A. Scientific}

Planetarium is a public education institution, and it popularizes astronomical knowledge and spread scientific thought to the public as the main objective. Scientific is the prominent feature of the planetarium exhibition project, it means that each exhibit must accurately convey the scientific principle or application, not spread false, superstitious and even reactionary contents. The choice of knowledge point should be comprehensive and fundamental, in order to make people fully understand astronomical knowledge and realize that obtaining scientific achievements is a step by step process. So the design of exhibition project must have profound scientific principles but be easy to understand [2].

\section{B. Systemic}

Systemic principle is to concatenate and organize the knowledge point which has the theme of storyline under the guidance of the show's core idea and theme from a macro point of view.

And there should be specific relationship between each exhibit. The purpose of exhibition is not really to convey a certain concept, the more important is to show a complete system through several interrelated exhibits [3]. This can not only create a good atmosphere for scientific exploration, but also be more beneficial to the participants to understand and master the implicit knowledge of science.

\section{Epochal character}

It means that design should be towards modernization, the world and the future. The concept of the exhibition keeps pace with the times and close to the times. The choice of topic is tightly around the forefront of astronomical hot issues in recent years, such as the super-moon, meteorite crashed in Russia, solar active maximum year, Chinese lunar rover to visit "Moon Palace" and so on. Starting from astronomical hot issues in the public interests, and spreading to the public the astronomical knowledge related to the hot issues, is able to stimulate the public curiosity, achieve good educational results better.

\section{Interesting}

It is necessary that use interesting design ideas and methods, in order to achieve better educational outcome, induce and inspire the audience's intrinsic factors, form the best state of mind, curiosity, concentration and so on[4]. Exhibition project require highly interactive and be easy to participate. It focus on teaching in happiness, when people operate and interact with exhibits, they produce a cooperative or competitive relationship between each other, which make the exhibition project more entertaining.

\section{E. Artistry}

It refers to the appearance of gallery and exhibit, including modeling, color, ergonomics and so on. If these aspects are conducted well, it can give people a good sensorial experience and make people produce the desire of participation and interaction. Therefore, we should use basic design principles like color semantics, aesthetics, ergonomics, design psychology and other subjects synthetically to plan and design the exhibition project of planetarium reasonably and scientifically, in order to meet the public aesthetic psychological and emotional need.

\section{CONCLUSIONS}

With the development of the times and the improvement of living standards, people have not only satisfied the needs of the material, they pursue deeper emotional needs. Science and technology museum should be a place where the public can be taught for life, it should grasp and understand the needs of the audience as much as possible, to attract the audience come and visit again and again[5]. Therefore, it is necessary to analyze the requirement of target user and master the relative intact survey data before planetarium exhibition project design, so that make the designers know what problems need to be solved, how to solve these problems for the exhibition project exactly, thus guide and conduct design activities more effectively.

\section{REFERENCES}

[1] Yuan Lu. User research of science and technology museum. Science Communication, 10, pp.12-13,2011.

[2] Canhui Lai. Discussion on the planning and development of innovation exhibition in science and technology museum. China New Technologies and Products, 12, pp.247-248,2009.

[3] Timao Huang. A study on innovation of the science and technology museum exhibition. Science popularization, 1, pp.76-82,2011.

[4] Xiaolong Wu. Discussion on selection and design principles of science and technology museum exhibition. Heilongjiang Science and Technology Information, 10, pp.53,2008.

[5] Yu Ma, Jiecheng Liu. The domestic familiar display form in the application of science and technology museum. Science \& Technology Association Forum, 3, pp.157,2009. 